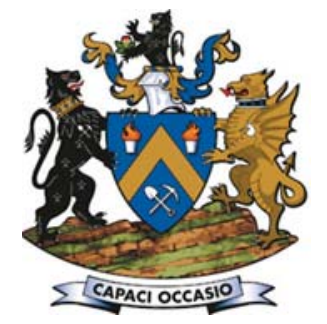

\title{
Conceptual use of vortex technologies for syngas purification and separation in UCG applications
}

\author{
by J.F. Brand* ${ }^{*}$, J.C. van Dyk*^, and F.B. Waanders ${ }^{\dagger}$
}

\section{Synopsis}

Syngas from Africary's Theunissen underground coal gasification (UCG) project will be used for power production and synthesis of liquid fuels and commodity chemicals. However, some of the coal components, especially condensable water, oils, tars, inorganic trace elements, and a small fraction of fly ash and particulate matter, make their way to the surface via the production well and can cause adverse impacts on downstream processes. Africary's standard design incorporates a cold gas clean-up system that relies on relatively mature techniques based on highly effective wet scrubbers and acid gas removal (AGR) systems such as Rectisol ${ }^{\circledR}$, but with the downside of low energy efficiency and waste water generation. In this paper, novel technologies for removing contaminants and species separation from the hot $\left(T>300^{\circ} \mathrm{C}\right)$ raw syngas are compared. Comparisons are made between supersonic gas separation (SGS), Ranque-Hilsch vortex tube (RHVT), vortex gradient separation (VGS), and inertia vacuum filtering (IVF), and a vortex-based gas separation concept is proposed for UCG applications.

Keywords

underground coal gasification, gas cleaning, supersonic gas separation, Ranque-Hilsch vortex tube, vortex gradient separation, inertia vacuum filter. the technical difficulties caused by extreme environmental and operating conditions.

High-temperature syngas cleaning has been the focus of research for over three decades (Sharma et al., 2008), but a scientifically proven and tested technology has not yet been commercialized. Significant improvements have been achieved with candle filters in the past few years (Prabhansu et al., 2015); however, these conventional warm gas cleaning technologies have fundamental limitations due to the intrinsic material properties of candle filters that cause practical problems and lead to unacceptable availability.

Sharma et al. (2008) presented the status of syngas cleaning technologies for particulate removal systems and reviewed the practical problems and limitations faced by these gas cleaning systems. Recommendations were also made to overcome these fundamental limitations. Gas clean-up technologies can generally be classified according to the process temperature range: hot gas clean-up (HGC), cold gas clean-up (CGC), or warm gas clean-up (WGC). There is considerable ambiguity in the literature around the definitions, and Woolcock and Brown (2013) propose a more rigorous classification based on condensation temperatures of various compounds. CGC generally describes wet scrubbing processes (Balas et al., 2014) that operate at nearambient conditions, utilizing water sprays, and which result in exit temperatures that allow water to condense and the contaminants either being absorbed into the water droplets or serving as nucleation sites for water condensation (Woolcock and Brown, 2013). WGC is often assumed to occur at temperatures higher than the boiling point of water but which still allow for ammonium

* African Carbon Energy, South Africa.

+ Centre of Excellence in Carbon based fuels, School of Chemical and Minerals Engineering, NorthWest University, South Africa.

(C) The Southern African Institute of Mining and Metallurgy, 2018. ISSN 2225-6253. Paper received Apr. 2018; revised paper received Jul. 2018. 


\section{Conceptual use of vortex technologies for syngas purification and separation}

chloride condensation. This typically implies a warm upper limit of temperatures of about $300^{\circ} \mathrm{C}$. HGC typically occurs at temperatures higher than $300^{\circ} \mathrm{C}$, at which it is still likely that several alkali compounds will condense (Hirohata et al., 2008).

UCG has the potential to produce raw syngas at the production well on surface that is both hot and at pressure; ideal for the Fischer-Tropsch (FT) process, which preferably requires the clean syngas to be at temperatures of $>250^{\circ} \mathrm{C}$ and pressures $>25 \mathrm{~atm}$. The preservation of both temperature and pressure during gas clean-up will greatly enhance the efficiency of the overall system. The syngas production pressure designed for Africary's Theunissen UCG project is 25 atm., based on hydrostatic pressure modelling, and the gas will reach the surface with a target temperature of 250 $350^{\circ} \mathrm{C}$.

In this study the aim is to address the fundamental limitations and practical constraints of existing hot particulate removal technologies. These systems generally suffer from poor availability caused by factors associated with tensile strength, the sealing system, thermal transient behaviour, corrosion, and residual ash accumulation (Hirohata et al., 2008). These problems can be circumvented by introducing alternative hot gas separation and/or cleaning methods such as supersonic gas separation (SGS), RanqueHilsch vortex tube (RHVT), and vortex gradient separation (VGS) with inertia-vacuum filter (IVF). A vortex-based gas separation concept is proposed for UCG applications.

\section{Description of Africary's UCG syngas content and contaminants}

Contaminants generally include particulate matter (mineral particulates, trace elements, and char), water vapour, condensable hydrocarbons (oils and tars), sulphur compounds, nitrogen compounds, alkali metals (primarily potassium and sodium), and hydrogen chloride ( $\mathrm{HCl})$. The sulphur compounds and $\mathrm{CO}_{2}$ are usually removed by various adsorption-based acid gas removal systems, but novel alternatives like the SST, RHVT, and VGS are proposed for the vortex tube concept for UCG applications.

The major syngas constituents and the predicted contaminants expected from the UCG production well are based on experimental work (van Dyk, Brand, and Waanders, 2014). The results are presented in Table I. Water, in the form of steam, is removed to dry the syngas by washcooling the gas to below its saturation temperature. This allows some condensable hydrocarbons like oils and tars to be removed with the water. Some of the water-soluble gases like ammonia are also removed during this process. The tars consist of condensable organic compounds and may vary from primary oxygenated products to heavier deoxygenated hydrocarbons and polycyclic aromatic hydrocarbons (PAHs) (Africary, internal modelling work).

Thermochemical conversion processes generate numerous tar species depending on the operating parameters, especially temperature, pressure, heating rate, type and amount of agent/oxidant, and residence time (Africary, internal modelling work). A UCG gasifier may yield 1 to $3 \%$ (mass basis) tar; however, regardless of the amount or type, liquid hydrocarbons like tar and oil are a universal challenge because of their potential to foul filters, lines, and equipment, as well as deactivate catalysts in downstream processes (Torres, Pansare, and Goodwin, 2007). Although eliminating all tar and oil is desirable, a more practical strategy is to simply remove sufficient liquid hydrocarbons at a temperature lower than the minimum temperature that the gas is exposed to downstream.

Inorganic compounds and residual solid carbon from the UCG production well constitute the bulk of the particulate matter. The inorganic content includes alkali metals (potassium and sodium), alkaline earth metals (mostly calcium), silica $\left(\mathrm{SiO}_{2}\right)$ and alumina $\left(\mathrm{Al}_{2} \mathrm{O}_{3}\right)$, and other metals such as iron and magnesium (Africary, internal modelling work). Minor constituents present in trace amounts include arsenic, selenium, antimony, zinc, and lead (van Dyk and Keyser, 2014). Most nitrogen contaminants in syngas occur as ammonia $\left(\mathrm{NH}_{3}\right)$ with smaller amounts of hydrogen cyanide $(\mathrm{HCN})$.

Coal from the Northern Free State Basin, South Africa, which will be used for the Theunissen UCG project, contains alkali and alkaline earth metals. The alkali metals are primarily potassium and to a lesser extent sodium, and are more problematic in syngas applications than alkaline earth metals due to their higher reactivity and potential to form substrates with halides like $\mathrm{Cl}$ and $\mathrm{F}$.

\section{Table I \\ The two types of raw syngas that can be produced from Theunissen UCG project (Africary, internal modelling work)}

\begin{tabular}{|c|c|c|}
\hline Streams & Raw gas 1 & Raw gas 2 \\
\hline Components & $\mathrm{mol} \%$ & $\mathrm{~mol} \%$ \\
\hline $\begin{array}{l}\mathrm{H}_{2} \\
\mathrm{CO} \\
\mathrm{CO}_{2} \\
\mathrm{CH}_{4} \\
\mathrm{C}_{2} \mathrm{H}_{4} \\
\mathrm{~N}_{2} \\
\mathrm{O}_{2} \\
\mathrm{H}_{2} \mathrm{O} \\
\mathrm{H}_{2} \mathrm{~S}+\mathrm{COS}\end{array}$ & $\begin{array}{l}34.5 \% \\
46.0 \% \\
7.3 \% \\
7.0 \% \\
0.0 \% \\
0.6 \% \\
0.0 \% \\
4.4 \% \\
0.2 \%\end{array}$ & $\begin{array}{c}43.1 \% \\
27.5 \% \\
9.6 \% \\
12.4 \% \\
0.0 \% \\
0.6 \% \\
0.0 \% \\
6.6 \% \\
0.2 \%\end{array}$ \\
\hline Trace & \multicolumn{2}{|c|}{$\mathrm{mg} / \mathrm{h}$} \\
\hline $\begin{array}{l}\mathrm{Ba} \\
\mathrm{Sb} \\
\mathrm{Cd} \\
\mathrm{Cr} \\
\mathrm{Be} \\
\mathrm{Pb} \\
\mathrm{Mo} \\
\mathrm{Cu} \\
\mathrm{Co} \\
\mathrm{Mn} \\
\mathrm{Hg} \\
\mathrm{Sn} \\
\mathrm{As} \\
\mathrm{Ni} \\
\mathrm{Zn} \\
\mathrm{V} \\
\mathrm{Cl} \\
\mathrm{F}\end{array}$ & $\begin{array}{l}1.3 \mathrm{E}-19 \\
1.4 \mathrm{E}+04 \\
2.5 \mathrm{E}-02 \\
7.4 \mathrm{E}-20 \\
3.1 \mathrm{E}-07 \\
2.2 \mathrm{E}-02 \\
2.8 \mathrm{E}-14 \\
1.6 \mathrm{E}-17 \\
8.4 \mathrm{E}-27 \\
1.2 \mathrm{E}-26 \\
9.2 \mathrm{E}+02 \\
9.5 \mathrm{E}+02 \\
7.6 \mathrm{E}-01 \\
1.0 \mathrm{E}-13 \\
7.4 \mathrm{E}-04 \\
5.8 \mathrm{E}-14 \\
1.4 \mathrm{E}+06 \\
2.1 \mathrm{E}+05\end{array}$ & $\begin{array}{l}1.2 \mathrm{E}-19 \\
1.3 \mathrm{E}+04 \\
2.3 \mathrm{E}-02 \\
6.8 \mathrm{E}-20 \\
2.8 \mathrm{E}-07 \\
2.0 \mathrm{E}-02 \\
2.6 \mathrm{E}-14 \\
1.5 \mathrm{E}-17 \\
7.8 \mathrm{E}-27 \\
1.1 \mathrm{E}-26 \\
8.5 \mathrm{E}+02 \\
8.8 \mathrm{E}+02 \\
7.1 \mathrm{E}-01 \\
9.6 \mathrm{E}-14 \\
6.8 \mathrm{E}-04 \\
5.4 \mathrm{E}-14 \\
1.3 \mathrm{E}+06 \\
1.9 \mathrm{E}+05\end{array}$ \\
\hline Liquids & \multicolumn{2}{|c|}{$\mathrm{kg} / \mathrm{h}$} \\
\hline $\begin{array}{l}\text { Tar } \\
\text { Oil } \\
\text { Naphtha }\end{array}$ & $\begin{array}{l}310 \\
305 \\
160\end{array}$ & $\begin{array}{l}290 \\
280 \\
145\end{array}$ \\
\hline
\end{tabular}




\section{Conceptual use of vortex technologies for syngas purification and separation}

Common issues with particulate matter are fouling, corrosion, and erosion, which cause efficiency and safety concerns if not removed or addressed before syngas processing. For example, due to the inclusion of gas engines and compressors in the Africary Theunissen UCG plant, the particulate content must be reduced to below $1 \mathrm{mg} / \mathrm{m}^{3}$. Particulate matter is classified according to aerodynamic diameter. For instance, PM10 denotes particles smaller than $10 \mu \mathrm{m}$, and PM1 particles smaller than $1 \mu \mathrm{m}$ (Federal Remediation Technologies Roundtable, 2016). It is common practice to remove particulates of a certain size to below a given level, as indicated in Tables II and III.

Alkali compounds reaching the surface in the form of chlorides, hydroxides, and sulphates can cause substantial fouling and corrosion in downstream processes. Chlorides are the predominant halide in syngas, usually in the form of hydrochloric acid ( $\mathrm{HCl})$. Chlorine in coal occurs as alkali metal salts, which readily vaporize at the high gasification temperature and react with water vapour to form $\mathrm{HCl}$. Substantial hot corrosion can occur, and reactions can also occur between $\mathrm{HCl}$ and other contaminant species in the gas phase, which can generate compounds such as ammonium chloride $\left(\mathrm{NH}_{4} \mathrm{Cl}\right)$ and sodium chloride $(\mathrm{NaCl})$ which cause fouling in downstream equipment upon cooling.

\section{UCG syngas clean-up requirements for polygeneration}

When a UCG plant is operated in a stable and correct manner, much less particulate and mineral matter is produced in the raw syngas compared to conventional gasification operations and only a small amount of particulate removal is required. However, the raw syngas may still contain a lot of moisture, tars, and oils, requiring removal. CGC relies on mature techniques, like wet scrubbers, that are decidedly effective but generate waste water and have poor energy efficiency and a large environmental footprint.

The level of cleaning that is required is based on the downstream consumer's technology requirements, fuel specification, and emission standards. For Africary's UCG polygeneration (power and diesel fuel) design, the cleaned syngas product specification is defined by the feed specification for the FT process vendor (Table II), and/or the gas engine vendor (Table III).

The liquid fuel products produced by the FT unit must follow the Euro-5 specification, as required by South African legislation, therefore removal of $\mathrm{HCN}, \mathrm{NH}_{3}, \mathrm{Hg}, \mathrm{Sb}, \mathrm{Sn}$, sulphur compounds, metals, halogens ( $\mathrm{Cl}$ and $\mathrm{F}$ ), and several other trace components is required (Prabhansu et al., 2015; correspondence with several FT process licensors). The syngas clean-up system must dry the raw syngas and effectively capture (> 99.9\%) all the trace elements listed in Table I, as well as remove all particulate matter. It also needs to effectively separate (>99.99\%) acid gases like $\mathrm{H}_{2} \mathrm{~S}$, COS, and $\mathrm{CO}_{2}$ from the syngas, with an availability factor above $98 \%$.

Separating at least $85 \%$ of all the $\mathrm{H}_{2}$ and $\mathrm{CH}_{4}$ from the raw gas 1 stream to augment the $\mathrm{H}_{2}$ : $\mathrm{CO}$ ratio of raw gas 2 stream is highly desired. As a second step, $\mathrm{CO}_{2}$ separation from sulphur and capturing the sulphur either as organic or sulphuric acid will be desirable.

\section{Cold gas clean-up - wet scrubbing}

The cold gas clean-up (CGC) system is the predominant gas treatment technology chosen for UCG in combination with gas engines due to its proven reliability (Balas et al., 2014). For the Africary Theunissen UCG process design, a cyclone in combination with a wet scrubber system can be implemented for power generation. The system will recirculate and cool water to remove the moisture, tar, oil, and particulates by wet scrubbing and may include lime dosing as sulphur adsorbent and pH control (National Lime Association, 2007; Wang, Pereira, and Hung, 2005).

Table II

Post clean-up syngas specifications for FT (Prabhansu et al., 2015; correspondence with several FT vendors

\begin{tabular}{l|c}
\hline Components/ properties & Limit value \\
\hline Heavy metals & $<1 \mathrm{ppm}_{\mathrm{w}}$ \\
\hline Silica & $<0.1 \mathrm{ppm}_{\mathrm{w}}$ \\
\hline $\mathrm{O}_{2}$ & $<1 \mathrm{ppm}_{\mathrm{w}}$ \\
\hline Halogens as $\mathrm{H}-\mathrm{X}(\mathrm{HCl}$ etc.) & $<5 \mathrm{ppb}_{\mathrm{w}}$ \\
\hline Alkali metals & $<10 \mathrm{ppb}_{\mathrm{w}}$ \\
\hline Soot/dust/solids & $<1 \mathrm{ppm}_{\mathrm{w}}$ \\
\hline Tars and aromatic components & $<1 \mathrm{ppm}_{\mathrm{w}}$ \\
\hline Nitrogen compounds, including $\mathrm{NH}_{3}$, & $<10 \mathrm{pp}_{\mathrm{bc}}$ \\
\hline $\mathrm{HCN}$, and amines & $<5 \mathrm{ppb}_{\mathrm{w}}$ \\
\hline Sulphur (including $\mathrm{H}_{2} \mathrm{~S}$ and organic sulphur) & $>30 \%$ \\
\hline $\mathrm{CO}$ & $>60 \%$ \\
\hline $\mathrm{H}_{2}+\mathrm{CO}$ & $\mathrm{H}_{2} \mathrm{O}:$ saturated at syngas \\
\hline Wet gas dew point & temperatures up to $50^{\circ} \mathrm{C}$ \\
\hline
\end{tabular}

Table III

Gas engine fuel gas specifications (Prabhansu et al., 2015; Balas et al., 2014; Scheibner and Wolters, 2002; correspondence with several gas engine vendors)

\begin{tabular}{l|c}
\hline Components/ properties & Limit value \\
\hline Sulphur & $<1200 \mathrm{ppmv}$ \\
\hline Hydrogen sulphide equivalent & $<1500 \mathrm{ppmv}$ \\
\hline Total sulphur compounds & $<57 \mathrm{mg} / \mathrm{MJ}$ or $2000 \mathrm{mg} / 10 \mathrm{kWh}$ \\
\hline $\mathrm{O}_{2}$ & $<2 \% \mathrm{v}$ \\
\hline $\mathrm{C} 4$ and higher & $<2 \% \mathrm{v}$ \\
\hline $\mathrm{H}_{2}$ & $<40 \%$ of total LHV \\
\hline Gas humidity & $<60 \%$ \\
\hline Wet gas dew point & $<15^{\circ} \mathrm{C} \mathrm{below} \mathrm{gas} \mathrm{temperature}$ \\
\hline Silicon and siloxanes & $<0.56 \mathrm{mg} / \mathrm{MJ}$ or $0.2 \mathrm{mg} / 10 \mathrm{kWh}$ \\
\hline Chlorine equivalent & $<3.5 \mathrm{mg} / \mathrm{MJ}$ or $400 \mathrm{mg} / 10 \mathrm{kWh}$ \\
\hline Ammonia & $<1.5 \mathrm{mg} / \mathrm{MJ}$ or $55 \mathrm{mg} / 10 \mathrm{kWh}$ \\
\hline Oils and tar & $<1.19 \mathrm{mg} / \mathrm{MJ}$ or $5 \mathrm{mg} / 10 \mathrm{kWh}$ \\
\hline Particulate matter (soot, dust, ash) & $<1-3 \mu \mathrm{m} \mathrm{and}$ \\
\hline Calorific value (CV) & $<0.8 \mathrm{mg} / \mathrm{MJ}$ or $50 \mathrm{mg} / 10 \mathrm{kWh}$ \\
\hline Temperature & $4.7-7.6 \mathrm{MJ} / \mathrm{Nm}{ }^{3}$ \\
\hline Pressure & $<40^{\circ} \mathrm{C}$ \\
\hline
\end{tabular}




\section{Conceptual use of vortex technologies for syngas purification and separation}

To minimize the wet scrubbing thermal penalty for FT, Africary will utilize a dual-stage cooling process, whereby the syngas will be cooled to approximately $150^{\circ} \mathrm{C}$ in the first stage before being introduced to the warm gas desulphurization (WGD) system. A portion of this syngas will be used as the fuel gas stream and further wash-cooled in a second stage to $80^{\circ} \mathrm{C}$. An additional trim water cooler will ensure that the fuel gas meets gas engine vendor requirements of $<40^{\circ} \mathrm{C}$ (Clarke Energy, 2016 personal communication). Wet scrubbing technology is considered the norm and state-of-the-art, as it deals with most of the condensable liquids and particulates. However, it only removes portions of the gaseous contaminants and does not perform any gas separation, and will therefore have to be used in conjunction with a separate acid gas removal (AGR) system. Further cooling of the syngas in the AGR system may reduce the temperature to as low as $-62^{\circ} \mathrm{C}$ (the condensation point of chilled methanol) and the syngas must be heated afterwards.

\section{Warm gas clean-up}

Warm and hot gas cleaning technologies are attractive to avoid cooling and reheating of the gas stream as required for CGC. Existing technologies for gas cleaning at warm temperatures $\left(<300^{\circ} \mathrm{C}\right)$ include cyclones, candle filters (for removing solid contaminants), molecular sieve membranes (for gas separation), and sorbents (for removing sulphurcontaining compounds (RTI LLC, 2018).

\section{Molecular sieves}

Carbon molecular sieve membranes are in development for the separation and purification of hydrogen from syngas. The potential benefits of high-temperature gas separation and membrane reactor processes are substantial; however, commercialization still remains elusive. A major technical barrier is the lack of robust inorganic membranes and fullscale modules that are suitable for use at the hightemperature and high-pressure conditions required (Parsley et al., 2014). According to a supplier, hydrogen seems the most suited for gas separation with molecular sieves; however, the gas must be free from all sulphur-containing compounds, making it infeasible for raw syngas processing.

\section{Candle filters}

Despite decades of research with metallic filters (Sharma et al., 2008), the materials have achieved only limited commercial success due to a natural correlation between porosity, mechanical strength, and thermal conductivity. Increasing the porosity of the material to increase the filtration area leads to a decrease in mechanical strength. This is a fundamental limitation for candle filters. An increase in the porosity increases both the filtering rate and surface area $\left(\mathrm{m}^{2} / \mathrm{g}\right)$, but decreases the mechanical strength and thermal conductivity and accelerates the corrosion rate.

Significant improvements in candle filters have been achieved in the past few years (Prabhansu et al., 2015); however, the reliability of these systems has never been successfully tested in a commercially integrated gasificationbased system environment. From the literature (Swanson and Hajicek, 2002; Guan et al., 2008), it is evident that most candle filters have operated for only a short period of a few thousand hours at $400^{\circ} \mathrm{C}$, although they last much longer at lower temperatures of around $285^{\circ} \mathrm{C}$ (Scheibner and Wolters, 2002) in a coal gasification environment. Even the use of exotic state-of-the-art metals and ceramics has provided only limited success. The failure of candle filters after a short period of operation leads to an uneconomical plant availability factor and higher operating cost than for CGC and they are therefore not widely used.

Warm-temperature candle filter technology deals with most of the particulates; however, it removes only a portion of the contaminants and does not remove any condensable liquids or alkali metals, nor does it perform gas separation, and it will therefore have to be used in conjunction with a separate AGR and CGC wet scrubber system.

\section{Hot gas clean-up}

\section{Supersonic gas separation}

A theoretical approach by Sforza, Castrogiovanni, and Voland (2012) shows that supersonic gas separation (SGS) has promise as a robust method for hot separation of fuel species ( $\mathrm{CO}, \mathrm{CH}_{4}$, and $\mathrm{H}_{2}$ ) from $\mathrm{H}_{2} \mathrm{O}, \mathrm{CO}_{2}$, and $\mathrm{H}_{2} \mathrm{~S}$ obtained from coal-derived syngas. They performed calculations based on general Lurgi-based gasification syngas input (31 atm., $450^{\circ} \mathrm{C}$ and $210000 \mathrm{Nm} 3 / \mathrm{h}$ ) for a concept that performs segregation by condensation of some of the gases.

This process is illustrated in Figure 1. A particulate-free, hot, wet syngas enters a chamber with an arrangement of static blades or wings, which induce a fast swirl in the gas. Thereafter the gas stream flows through a Laval nozzle, where it accelerates to supersonic speeds and undergoes a pressure drop to about $30 \%$ of feed pressure. Supersonic isentropic expansion results in a rapid decrease of temperature $\left(-80^{\circ} \mathrm{C}\right.$ to $\left.-115^{\circ} \mathrm{C}\right)$ and pressure, leading to the sequential condensation (and/or solidification) of $\mathrm{H}_{2} \mathrm{O}, \mathrm{CO}_{2}$, $\mathrm{H}_{2} \mathrm{~S}, \mathrm{NH}_{3}, \mathrm{HCN}$, and $\mathrm{COS}$, which form a fine mist including some liquid hydrocarbons (Secchi, Innocenti, and Fiaschi, 2016) like ethane, propane, and butane. The mist droplets agglomerate to larger drops, and the swirl of the gas causes cyclonic separation.

The dry gas, consisting of $\mathrm{H}_{2}, \mathrm{CO}, \mathrm{N}_{2}, \mathrm{CH}_{4}$, and $\mathrm{Ar}$, continues through the separator, while the liquid phase, together with some slip gas (about $15 \%$ to $30 \%$ of the total stream), is separated by a concentric divider and exits the device as a separate stream. In the final section both streams are diffused back to subsonic conditions; the gas is slowed down and about $50 \%$ to $80 \%$ (Netušil and Ditl, 2012) of the feed pressure and temperature (depending on application) is recovered.

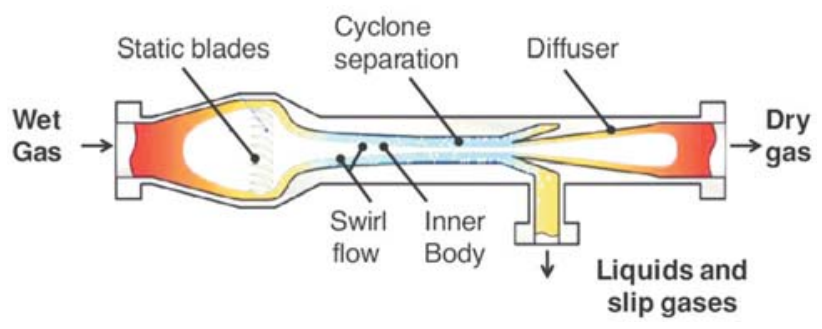

Figure 1-Schematic diagram of the supersonic gas separator for natural gas dehydration (Netušil and Ditl, 2012) 


\section{Conceptual use of vortex technologies for syngas purification and separation}

Such mechanical separators have no moving parts and a very small environmental footprint. However, the commercial use in drying natural gas from wells that inherently provide gas at very high pressures and modest temperatures is far different from the hot syngas cleaning proposal of Sforza, Castrogiovanni, and Voland (2012). In practice, the presence of any particulate matter in syngas travelling at supersonic speeds will result in a high probability of erosion, and further problems like hydrate plugging, flow rate inflexibility, and narrow turndown ratio (Haghighi, Hawboldt, and Abdi, 2015) have been reported. Furthermore, Netušil and Ditl (2012) stated that a $27.6 \%$ pressure loss is required for a separation efficiency of $90 \%$ moisture and $>50 \%$ for $>95 \%$ separation, showing diminishing returns for deep cleaning and recompression of the syngas might be required.

Condensing diverse gas mixtures into sizeable drops for accumulation and separation remains commercially untested, but Theunissen et al. (2011) proposed a rotational particle separator device to assist nucleation to reach the required size for cyclonic separation (> $15 \mu \mathrm{m})$.

\section{Ranque-Hilsch vortex tube}

The RHVT is a mechanical device with no moving parts that separates ambient temperature compressed gas into hot and cold streams. The gas emerging from the 'hot' end can reach temperatures of $200^{\circ} \mathrm{C}$, and the gas emerging from the 'cold' end can reach $-50^{\circ} \mathrm{C}$. Pressurized gas is injected tangentially into a swirl chamber and accelerated to a high rate of rotation. A conical nozzle at the end of the tube allows only the outer shell of the compressed gas to escape at the hot end, while the remainder of the gas returns in a smaller inner vortex within the outer vortex towards the cold end.

The working principle (see Figure 2) can be approximated as follows (Xue, Arjomandi, and Kelso, 2013).

(1) The adiabatic expansion of the incoming gas cools the gas and turns its heat content into kinetic energy of rotation while the total enthalpy is conserved.

(2) The outer rotating gas flow moves towards the hot end outlet. The kinetic energy of rotation allows for friction and turns into heat by the means of viscous dissipation, and the temperature of the gas rises to higher than that of the incoming gas.

(3) A portion of the gas exits at the cold outlet and obeys the traditional notion (the Joule-Thompson effect) in that temperature drops with a decrease in pressure.

(4) Heat is transferred between the quickly rotating outer flow and the opposite, slowly rotating, smaller internal axial flow, allowing for heat transfer from the cold to the hot vortex. A zone of no mixing exists between the two, allowing separation based on temperature.

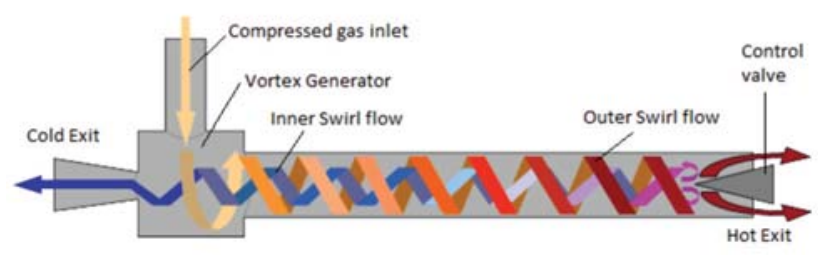

Figure 2-Flow structure inside a Ranque-Hilsch vortex tube (Netušil and Ditl, 2012)
The literature shows (Linderstrom-Lang, 1964, 1966) that partial separation of the components of a gas mixture occurs when it is passed through a RHVT. Marshall (1976) confirmed this effect using different gas mixtures and different sizes of tubes. He also studied the effect of reduced inlet and outlet pressures and found that if the outlet pressure is substantially below atmospheric, the separation factor is higher than the predicted correlation he derived (Marshall, 1976). This suggests that the performance can be improved by operating the vortex tube at vacuum pressure, which is also described further in the VGS technology description and indicates that the cut ' $\theta$ ' at which the peak separation appears was generally at about 0.4 , but varied for different settings between 0.2 and 0.6 (Wikipedia, 2018). This means that a RHVT can generally double the feed percentage of light species to the light side and double the heavy species to the heavy side. However, as a pure separation system the RHVT had poor performance and could only achieve an $\alpha$ value of approximately 1.025 , indicating a very low separation efficiency. This led to more focused research on the heat separation capability of an RHVT than on the gas species separation capability.

In the late 1990s renewed interest in the technology was shown, with more focus on cryogenic air separation for space transportation and new work yielded a promising $80-85 \%$ oxygen enrichment with a recovery in the 30-36\% range (Binau, 1997), but also poor results using an oversized RHVT (Spracklen, 1998). Balepin, Rosshold, and Petley (1999) claimed that the best performance for air separation occurred with a $68 \% \mathrm{O}_{2}$ concentration, with a $38 \%$ recovery factor and highest concentration of $85-90 \% \mathrm{O}_{2}$ but with only a $7-10 \%$ recovery factor.

Kulkarni and Sardesai (2002) studied the application of a RHVT to enrich the methane concentration in gas from production wells. The experiments conducted on separating $\mathrm{CH}_{4}$ from $\mathrm{N}_{2}$ confirmed that gas separation does occur in a vortex tube. The inlet pressure was found to be the most dominant factor affecting separation, and the maximum separative power attained was $5.5 \times 10^{+7} \mathrm{~kg} \cdot \mathrm{mol} / \mathrm{min}$.

Farouk, Farouk, and Gutsol (2009) simulated temperature, pressure, mass density, and species concentration fields within the vortex tube and found that even though a large temperature difference was obtained, only minuscule gas separation occurred due to diffusion effects. An investigation of the correlations between velocity, temperature, and species mass fraction revealed that the inner core flow has a large Eddy heat flux and Reynolds stresses that adversely influence the gas separation efficiency. Dutta, Sinhamahapatra, and Bandyopadhyay (2011) supported this finding, and observed that although the separation of air into its main components (oxygen and nitrogen) occurred, the separation effect was very small and the process of species separation was driven mainly by Soret diffusion. It is, however, notoriously difficult to separate streams like air, where the components have very similar molar mass densities. The accurate measurement of $\mathrm{O}_{2}$ and $\mathrm{N}_{2}$ concentrations is also difficult to manage and may require specialized set-up and calibration conditions.

More recent research has indicated encouraging performance for a RHVT. Chatterjee, Mukhopadhyay, and Vijayan (2017) developed and published a one-dimensional 


\section{Conceptual use of vortex technologies for syngas purification and separation}

mathematical model that can compute mass transfer based on inlet pressure, temperature, inlet concentration and flow rate and outlet pressure, temperature, and flow rate. This model can be used for rapid design and simulation of species separation in an RHVT. The model considers simultaneous heat and mass transfer in a RHVT. A set of experiments was carried out with three vortex generators of different capacities to validate the mathematical model. Using the largest unit at a flow rate of $0.26 \mathrm{~m} 3 / \mathrm{s}$ the oxygen concentration was boosted from the normal $21 \%$ to almost $28 \%$ for an $\alpha>1.45$ with recovery in the $10-15 \%$ range. If this performance can be repeated with a feed stream containing species with large variation in molar mass, then the level of separation may well be in the commercial application range for a UCG flow scheme; where the pressure has to be let down anyway and a slight increase in temperature could easily be accommodated by the trim cooler.

Brand and Esterhuyse (2018) conducted similar experiments with air using a commercial RHVT. Their results, as shown in Table IV, indicate that separation of air occurred, but the calculated error of $\pm 3 \%$ limits the accuracy of the measurement. Each sample was run twice, and the averages are reported in Table IV. The control sample of atmospheric air was run eight times, while a 95\% confidence interval was used to determine an error of $\pm 3 \%$. The gas chromatograph used could measure the $\mathrm{N}_{2}$ content of a sample with an accuracy of $\pm 0.1 \%$; however, $\mathrm{O}_{2}$ and Ar were combined in a single measurement.

The first samples taken ( $\mathrm{C} 1$ and $\mathrm{H} 1$ at $25 \%$ cold side flow) provide the expected $\mathrm{O}_{2}$ decrease at the cold side $( \pm 0.5 \%)$ and increase of $\mathrm{O}_{2}$ at the hot side of about $1.6 \%$. However, the best results of about $2 \%$ increase in $\mathrm{O}_{2}$ at the cold side of the RHVT and about the same increase of $\pm 2 \% \mathrm{~N}_{2}$ at the hot side in the second samples, using a smaller $10 \%$ flow at the cold flow orifice, was unexpected. This runs counter to the initial assumption that the heavier $\mathrm{O}_{2}$ molecules will concentrate at the hot end while the lighter $\mathrm{N}_{2}$ molecules will concentrate at the cold end.

\section{Vortex gradient separation}

A vortex gradient separator (VGS) has no moving parts, and a series of guide vanes/static blades induces a fast swirling vortex in the outer gas, surrounding a central core that passes thorough nozzles and diffusers that separate dirty flue gas or raw syngas into three streams (Chentsov, Beloglazov, and Korsakov, 2009). Figure 3 shows a schematic drawing of a VGS.
A dirty gas stream, comprising a mixture of gases, is fed into the inlet parabolic nozzle (1), consisting of sections ' $\alpha$ ' and ' $\beta$ ', where the flow is accelerated and the outer gas tangentially accelerated by internal guide vanes/static blades (2). The outer gas flow is accelerated and rotated, while preserving its laminar flow structure by implementing a constant area change $(d A / d L)$, and by steadily increasing the tangential and axial acceleration. The constants for area change are determined experimentally, depending on the gas stream properties (temperature, viscosity, density), but should not exceed Re 100 000. The gas then enters section ' $\delta$ ', for laminar acceleration in a parabolic nozzle (3), again under constant area change. The gas then enters the vortex diffuser (4), where the rotation is accelerated, while the axial speed is decreased to perform initial separation. This separated gas is then again axially and tangentially accelerated in a paraboloid nozzle (5) and finally fed to a separation diffuser (6), a concentric divider where the stream is cut into light (7), medium (9), and heavy fractions (8).

The laminar vortex induces a higher pressure at the periphery, which allows heavy gas components such as sulphur dioxide to accumulate and collect in layers and the solid particles to coagulate in the centre (Figure 4)

(Korsakov, 2010). Thus, it becomes possible to remove heavy acidic and toxic gas components with the simultaneous withdrawal of any suspended particles and vapour from a dirty gas source.

Chentsov, Beloglazov, and Korsakov (2011) described the gas dynamic flow formed in the VGS as 'fast rotating' with 'negatively-strained intermolecular bonds' with the following qualities. (1) The available kinetic energy (the molecularkinetic motion of the gas molecules) is constrained. (2) The suspended particles transported by the gas are concentrated in the central zone of the channel in the form of a dust 'core'.

Table IV

Results for the RHVT air separation test (Brand and Esterhuyse, unpublished work)

\begin{tabular}{|l|c|c|c|}
\hline Sample number & $\mathbf{O}_{\mathbf{2}}$ (mol.\%) & $\mathbf{N}_{\mathbf{2}}$ (mol.\%) & Total (mol.\%) \\
\hline Control (air) & 22.3 & 75.9 & 98 \\
C1 & 21.8 & 76.0 & 98 \\
H1 & 23.9 & 77.0 & 101 \\
C2 & 24.1 & 75.9 & 100 \\
H2 & 22.8 & 77.6 & 100 \\
\hline
\end{tabular}

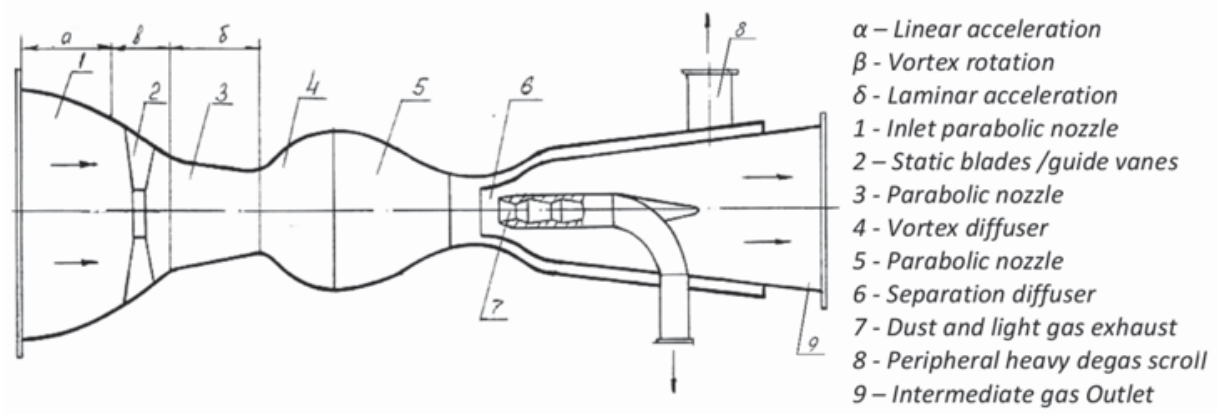

Figure 3-A typical vortex gradient separator (Chentsov, Beloglazov, and Korsakov, 2009) 


\section{Conceptual use of vortex technologies for syngas purification and separation}

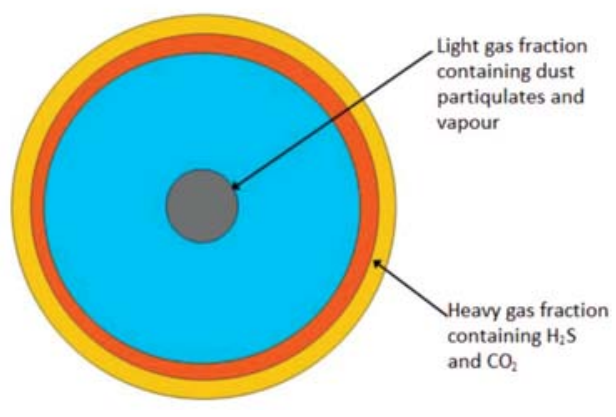

Figure 4-Cross-section of the gradient separator channel showing density variation (Korsakov, 2010)

Dust and aerosols are transported into the core from the rotating gas volume with the smaller size particles closer to the centre. (3) The VGS divides a gas mixture into its molecular components, based on their molecular weight and density, in the cross-section of the swirling channel, and the heavier gas components (like $\mathrm{SO}_{2}, \mathrm{CO}_{2}$, etc.) are distributed and collected in the peripheral zone.

In fluid dynamics, a negative pressure gradient, also called an adverse pressure gradient (APG), occurs when the static pressure increases in the direction of the flow. This is mathematically expressed as $d P / d x>0$ for a flow in the positive $\mathrm{x}$-direction. This is achieved by over-expanding a compressed gas into this 'negatively-strained' state. Gas in this state has many features that do not fit into the traditional molecular-kinetic theory, as the gas is basically flowing 'uphill' in the direction of the high pressure. This has an important impact on boundary layers, as increasing the fluid pressure is akin to increasing the potential energy of the fluid, leading to a reduced kinetic energy and deceleration of the gas while preventing laminar separation.

The principle observations associated with gas flow in an APG are (Korsakov, 2010):

1. In an APG, an axial gas flow accelerating in a converging nozzle maintains its laminar structure while transforming its potential energy into a laminar vortex.

2. If two streams containing dispersed dust particles in the 'over-expanded state' intersect, then the particles transfer to the jet with the highest velocity.

3. If a high-velocity gas stream travels over a large stationary gas volume separated by small slots, this large stationary gas volume acts as a 'sump' for suspended particles.

4. The thermal conductivity of the gas rises sharply. The thermal conductivity of air is usually $0.030-$ $0.035 \mathrm{~W} / \mathrm{mK}$, but for air in a negative-stressed state it increases 10 000-fold to 340-420 W/mK. Rank's effect also becomes more pronounced, i.e. the effect of the temperature distribution over the channel crosssection, decreasing the temperature in the centre of the channel cooler while increasing it at the periphery.

5. The heat transfer coefficient also increases 100-fold (gas to the separator wall) from the usual range of 20-60 W/m2K, to $2500-3000 \mathrm{~W} / \mathrm{m}^{2} \mathrm{~K}$.
The first two effects mentioned can be observed in nature where a 'dust devil' forms a funnel-like chimney that sucks dust particles into the centre of a vortex. A numerical simulation by $\mathrm{Gu}$ et al. (2006) based on an advanced dustdevil-scale, large-eddy simulation model verified that the horizontal inflow vortex could entrain solid particles and carry them into the vertical swirling wind field. Another trend identified was for the fine dust grains to rise along the inner helical tracks, while the larger dust grains were lifting along the outer helical tracks.

CFD modelling (Chentsov, Beloglazov, and Korsakov, 2011) shows the formation of a stable central vortex entering the separator nozzle. The peripheral rotation was estimated at around $3000 \mathrm{r} / \mathrm{min}$, while the rotation around the core reaches $100000 \mathrm{r} / \mathrm{min}$.

The Russian student website Studopedia (n.d.) provides insights into the working principles of the VGS as follows. An APG provides an inertial seal by increasing the strain of the gas to provide a contracting laminar vortex. This allows the density of the stream to increase towards the centre axis and to exceed the relative particle density. This allows any particulates to float on the gradient flow surface, creating a constant dust layer in the centre of the VGS channel.

Arguably the most detailed description of the principles of the VGS was published by Moiseev et al. (2016a). The focus of this paper was on separating less than $0.5 \%$ methane from a mine ventilation gas flow by recovering the methane in concentrations of up to $80 \%$. The authors further explain that the separation of the gas and dust flows within a VGS occurs towards the axial direction, due to the generation of several vortices including countercurrent flows, with sharp decreases in tangential velocity as can be seen in Figure 5. The CFD studies of a methane-dust-air mixture revealed the following features (see Figure 5) (Moiseev et al., 2016a).

1. A near-axial flow is swirled around the central axis and moves along it in the shape of a twisting and narrowing core.

2. A peripheral flow is swirled around the central axis (in the shape of a spiral) and moves more slowly down the axis of the gradient separator, resulting in the presence of a counter-return flow.

3. Pulsation occurs due to the high tangential velocity and radial pressure drop, resulting in cooling of the central/axial gas flow and heating of the peripheral flow, thus providing for the simultaneous concentration of lighter components.

4. Thermal energy fluxes result due to micro-cooling cycles of radial turbulent flows.

\section{Inertia vacuum filter}

The same APG principles that are used to separate dust particles and light gases in the VGS can also be used as a filter mechanism to filter micrometre-sized particulates from a gas. Moiseev et al. (2016b) evaluated an inertia vacuum filter (IVF) for removing particles from coal mines ventilation air. The unit was designed to clean a volume of 200000 $\mathrm{Nm}^{3} / \mathrm{h}$, using $500-570 \mathrm{~kW} / \mathrm{h}$. The particle removal efficiency was about $99.8 \%$ with the minimum size of the collected particles being $1 \mu \mathrm{m}$. In this device, gas containing dust particles is sucked/vacuumed through an accelerating nozzle (stream A in Figure 6). 


\section{Conceptual use of vortex technologies for syngas purification and separation}

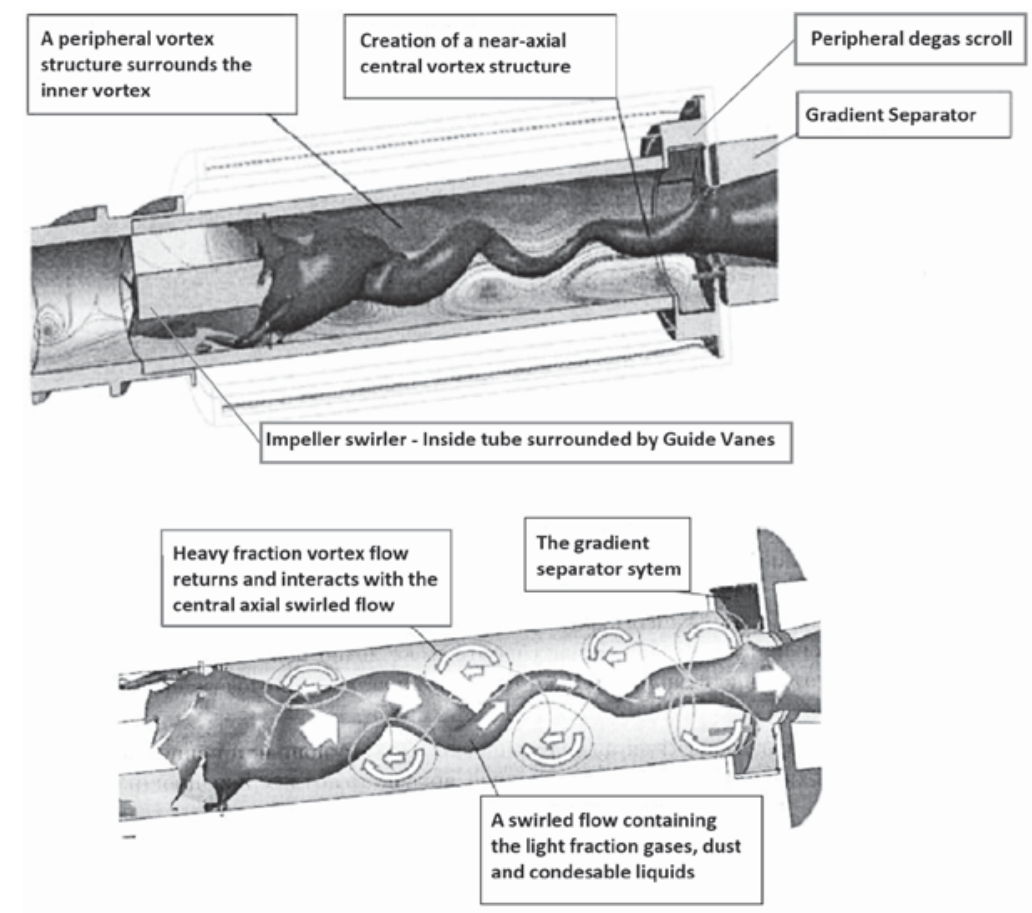

Figure 5-CFD model (Moiseev et al., 2016a) showing the same countercurrent vortex formation as described for RHVT (Dutta, Sinhamahapatra, and Bandyopadhyay, 2011)

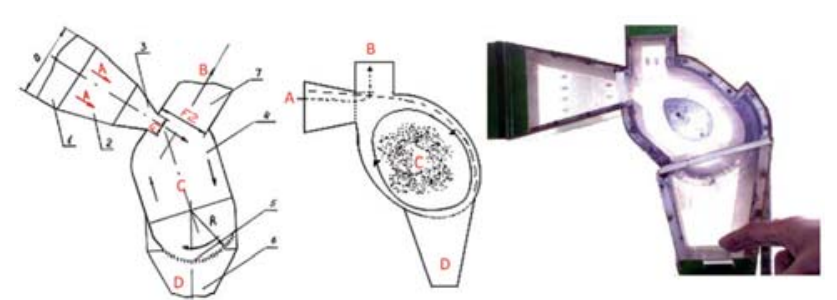

Figure 6-Schematic illustration of the principle of an inertia vacuum filter (Chenysov et al., 2009; Korsakov, 2010)

The area ' $F 1$ ' of the accelerating nozzle is smaller than the cross-section of the exit 'F2' and the velocity of the gas increases and expands in this section as the gas goes into an AGP state. The dusty input stream passing through the crosssection of F1 has a greater velocity than the stream in the cross-section of F2 and therefore the particles in this stream also have a higher velocity (greater kinetic energy), which allows them to overcome the drag force of slower exiting stream B (as the suspended matter from the two intersecting jets will be captured by the jet that moves fastest). This allows for two jets of APG gas to intersect and for the output stream to permeate the inlet stream with its particles and for the suspended particles to become trapped inside the circulating stream C.

While the two-phase gas circulates inside the rotary chamber (4), it passes over a precipitation grille (item 5 in Figure 6). This process creates an aerodynamic trap whereby particles can enter the rotary chamber of the device, but cannot exit and eventually settle in the collecting chamber (6). The gas circling the rotary chamber also becomes a highly efficient filter, consisting of layers of gas acting as layers of filtering material. About 2-3\% ultra-fine particles may accumulate in the rotating $\mathrm{C}$ stream, but eventually they also coagulate and fall into the collecting chamber.

Chentsov, Beloglazov, and Korsakov (2009) successfully tested a VGS combined with an IVF at the Ekibastuz coal power plant that removed fly ash with a particle size of 5$100 \mu \mathrm{m}$. The installation had a capacity of $15000 \mathrm{~m} 3 / \mathrm{h}$ and was equipped with measuring equipment with a measurement accuracy of $\pm 0.1 \mathrm{~g}$. Forty-five tests were carried out with up to -35 mbar vacuum, which achieved filtering of up to $99.25 \%$ of all particles, and with the latest upgrades operating at $99.99 \%$. Korsakov (2010) stated that the installation had been in operation for 4 years. Chentsov and Barsukov (2011) also tested an IVF device was at the Pavlodar power station boiler. Here, the device placed between the second stage economizer and the air pre-heater achieved 65 to $70 \%$ dust removal down to $1 \mu \mathrm{m}$.

\section{Characteristics of vortex separation for UCG}

Several dusty and wet syngas clean-up technologies have been considered for raw (wet and dirty) UCG syngas at different implementation temperatures, and these are summarized in Table V.

The incorporation of HGC based on vortex gas separation with IVF may provide both particle separation and gas separation directly from a UCG production well. The advantages of such a hot, wet, and dirty gas clean-up system in combination with RTI's Warm Gas Desulfurization process can provide for efficient syngas clean-up for clean coal power generation. This process can further be combined with deeper acid gas removal, and control of the carbon to hydrogen ratio may allow the efficient blending of syngas produced by different UCG operating regimes to supply a cost-effective FT syngas for polygeneration operations. 


\section{Conceptual use of vortex technologies for syngas purification and separation}

\begin{tabular}{|c|c|c|c|}
\hline \multicolumn{4}{|c|}{ Comparison of raw syngas clean-up technologies proposed for UCG } \\
\hline Temp. & Type & Advantages & Disadvantages \\
\hline Cold & $\begin{array}{l}\text { Wet } \\
\text { scrubbing }\end{array}$ & $\begin{array}{l}\text { Mature. State-of-the-art and widely used. Removes all } \\
\text { liquids, tars, solids. Adsorbents can remove all acid } \\
\text { gases to ppb level. Low pressure drop. }\end{array}$ & $\begin{array}{l}\text { Expensive, generates waste water, and has poor energy and thermal } \\
\text { efficiency. Reheating of syngas required. Large environmental } \\
\text { footprint. }\end{array}$ \\
\hline \multirow[t]{3}{*}{ Warm } & Cyclone & $\begin{array}{l}\text { Cheap. Modest pressure drop. Works well to } \\
\text { remove large particles. }\end{array}$ & $\begin{array}{l}\text { Cannot remove ultra-fine particles or liquids. Prone to fouling. } \\
\text { No gas separation. }\end{array}$ \\
\hline & $\begin{array}{c}\text { Candle } \\
\text { filter }\end{array}$ & Can remove very-fine particles from dry gas. & $\begin{array}{l}\text { Poor reliability. Cannot remove or tolerate tars and liquids. No gas } \\
\text { separation. Expensive and uses exotic materials. Moderate pressure drop. }\end{array}$ \\
\hline & $\begin{array}{l}\text { Molecular } \\
\text { sieve }\end{array}$ & $\begin{array}{l}\text { Can separate clean gases. } \\
\text { Can commercially separate } \mathrm{H}_{2} \text { and } \mathrm{CO}_{2} \text {. }\end{array}$ & Very low sulphur tolerance. Requires very clean and dry gas. \\
\hline \multirow[t]{5}{*}{ Hot } & RTI's WGD & $\begin{array}{l}\text { Removes sulphur compounds at high temperature. } \\
\text { Can tolerate and remove minor trace metals and } \\
\text { particulates. Low pressure drop. }\end{array}$ & $\begin{array}{l}\text { All liquids must be removed below the operating dew point. Cannot } \\
\text { remove } \mathrm{CO}_{2} \text { or condensable liquids. }\end{array}$ \\
\hline & SGS & $\begin{array}{l}\text { Commercialized for NG separation. Removes acid } \\
\text { gases to \% level. No moving parts. Possible removal } \\
\text { of liquids, tars, solids. }\end{array}$ & $\begin{array}{l}\text { May be damaged by particles. Can foul quickly. } \\
\text { Not experimentally proven on syngas. }\end{array}$ \\
\hline & RHVT & $\begin{array}{l}\text { Cheap. } \\
\text { No moving parts. } \\
\text { Modest separation of light species from heavy species. } \\
\text { May provide cooling/heating option. }\end{array}$ & $\begin{array}{l}\text { May be damaged by particles or liquids. Can foul quickly. Moderate } \\
\text { pressure drop. May create additional cooling or heating demand. Very } \\
\text { low separation factor and gas must be cascaded and recompressed for } \\
\text { high separation values. Not commercially tested as a separation device. }\end{array}$ \\
\hline & VGS & $\begin{array}{l}\text { Removes all liquids, tars, solids. Separates light species } \\
\text { from heavy species. Separates acid gases and light gases } \\
\text { to \% level. High separation factor. Commercially tested. }\end{array}$ & $\begin{array}{l}\text { Modest vacuum compressor demand. Requires independent verification } \\
\text { of published results. }\end{array}$ \\
\hline & IVF & $\begin{array}{l}\text { Can remove ultra-fine particles. } \\
\text { Low pressure drop. } \\
\text { Commercially tested. }\end{array}$ & $\begin{array}{l}\text { May foul quickly from liquids. Modest vacuum compressor demand. No } \\
\text { gas separation. Requires independent verification of published results. }\end{array}$ \\
\hline
\end{tabular}

\section{Proposed UCG application}

A conceptual novel UCG gas clean-up and separation unit design based on a VGS, cleaning raw syngas directly from the UCG production well is proposed. The concept will allow the hot and efficient separation of syngas into its useful components, together with partial cleaning for further gas utilization. As the UCG production well is pressurized the use of an axial flow pressure regulator will be required. This device must control the upstream flow in such a manner that the downstream compressors can vacuum the gas and allow the implementation of an APG of about $50 \mathrm{~mm} \mathrm{H}_{2} \mathrm{O}$ over the vortex separator and the filters. This modest vacuum requirement implies that the syngas well pressure is not reduced and that the power demand is kept relatively small compared to the total production plant requirements.

In a second step (see Figure 7) the incoming gas is separated and an initial vortex created by a stationary guide vane. The addition of a portion of recycled pure gas by a cyclone injector will impart significant tangential velocity to the outside of the incoming raw gas.

In a third step/chamber, the spinning gas will be allowed to intersect with the central dusty core (as described in the CFD studies), which will allow the transfer of dust to the central axial flow of light gases (mainly $\mathrm{H}_{2}$ and $\mathrm{CH}_{4}$ ), to be removed by the dust exhaust in the 'particle separation' step. This gas may be cooled with a steam-generating heat exchanger to protect the downstream vacuum compressors. Before the cooled gas is fed to the compressors it is passed through an IVF system or a CGC wet scrubbing system that will remove any condensable liquids and dust. This washed light fraction will be used for $\mathrm{H}_{2}$ : $\mathrm{CO}$ ratio control in the FT process.
In a fourth step the vortex speed is increased by internal guide vanes, which increases the pressure and density of the gases and allows the heavier molecular gases to move to the periphery, where they are removed by an inverted cyclone. The gas may be cooled to generate process steam and to protect the downstream vacuum compressors. Literature sources indicate that this heavy gas stream can be passed through a second-stage smaller VGS to separate the very heavy sulphur components from the $\mathrm{CO}_{2}$. The sulphur components will be routed to a sulphur recovery plant and the $\mathrm{CO}_{2}$ may be further processed on site.

The remaining cleaned gas (also called 'pure gas') is passed through the high-temperature booster-compressor, where a portion of the gas is recycled in the second step.

Although the proposed system may clean the syngas only partially it may still be reasonable to implement, as the removal of $99.9 \%$ of the particulates as well as acid gas will allow the use of smaller downstream equipment and guard beds instead of large process equipment.

\section{Conclusions}

The effectiveness and carbon efficiency of UCG can be improved by hot cleaning raw syngas directly from the UCG production well. The proposed vortex separation hot gas clean-up concept will allow for the removal of most of the particulates, together with the efficient separation of the syngas into its useful components, providing for acid gas removal and $\mathrm{H}_{2}: \mathrm{CO}$ ratio control. The most important principle for vortex separation is the preservation of laminar flow allowed by the adverse pressure gradient. Other technical and economic advantages may include, but are not limited to: 


\section{Conceptual use of vortex technologies for syngas purification and separation}

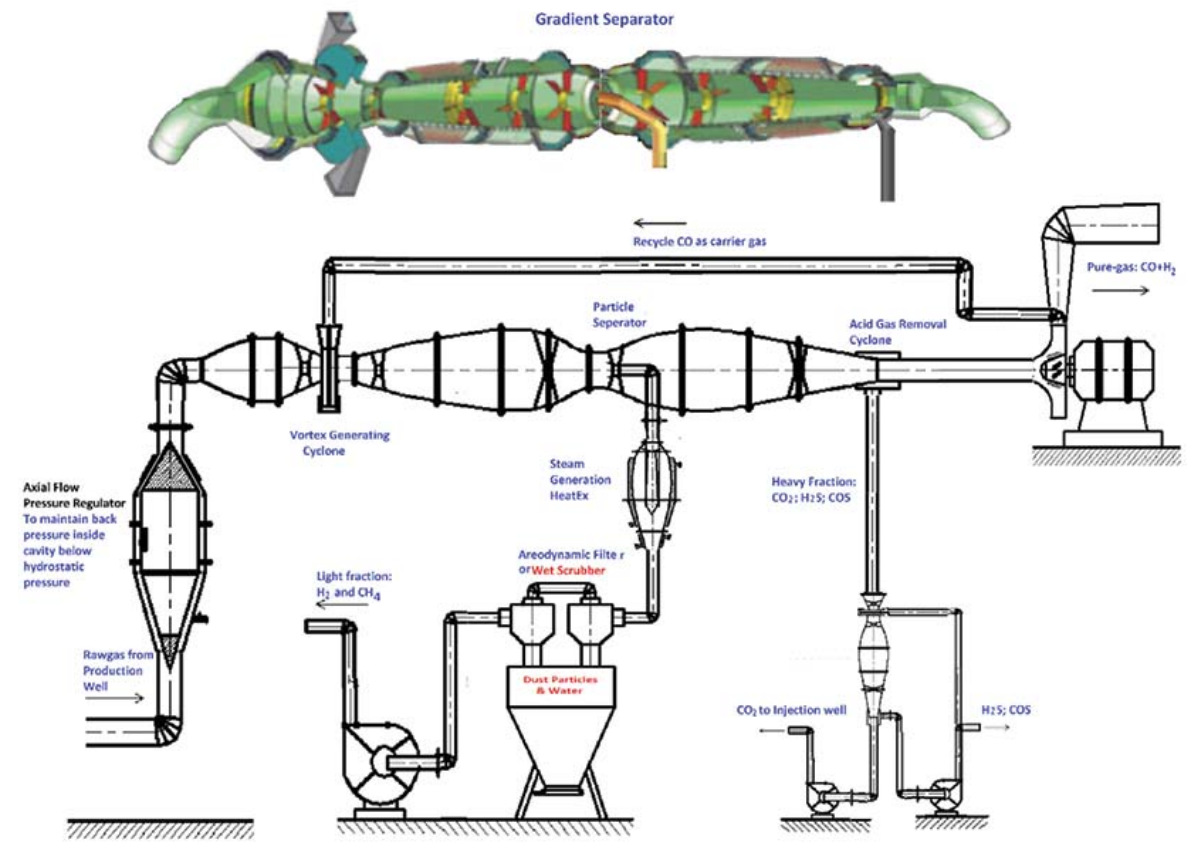

Figure 7-Diagram showing a proposal for hot gas clean-up of raw syngas from a UCG production well in several steps [adapted from Chenysov, Beloglazov, and Korsakov, 2009; Korsakov, 2010)

$>$ Removal of most of the condensable water, oils, tars, fly ash, and particulate matter directly from the hot syngas, allowing hot gas processing and pressure boosting.

> Removal of most of the $\mathrm{H}_{2} \mathrm{~S}$ and $\mathrm{CO}_{2}$, allowing for cheaper warm syngas desulphurization combined with guard beds, rather than low-temperature adsorption processes.

> Separation of $\mathrm{H}_{2}$ from a second syngas stream for $\mathrm{H}_{2}$ :CO ratio adjustment before FT and negating the need for a CO-shift rector with a subsequent $\mathrm{CO}_{2}$ avoidance.

The level of separation is in the commercial application range for the Theunissen UCG project as the syngas typically contains species with large variation in molar mass and the syngas pressure of the second stream used for power generation has to be let down anyway. Vortex separation specifically applied to a UCG process, is a practical solution to improve both energy efficiency and lower the $\mathrm{CO}_{2}$ footprint.

The next steps and future work will include the modelling, design, and experimental testing of a VGS for both particulate filtering and gas separation efficiency.

\section{Nomenclature}

AGR acid gas removal

APG adverse pressure gradient

atm. atmospheres / pressure ratio

CFD computational fluid dynamics

CGC cold gas clean-up

FT Fischer-Tropsch

GC gas chromatograph

HGC hot gas clean-up

IVF inertia vacuum filter

N1 mole fraction of heavier species at the inlet
N2 mole fraction of heavier species at hot outlet

N3 mole fraction of heavier species at cold outlet

PM2.5 $<2.5 \mu \mathrm{m}$ particulates

PM5 $<5 \mu$ m particulates

PM10 < $10 \mu$ m particulates

Re Reynolds number

RHVT Ranque-Hilsch vortex tube

SGS Supersonic gas separation

UCG underground coal gasification

VGS vortex gradient separation

WGC warm gas clean-up

$\alpha \quad$ separation factor for light species between product and feed streams

$=[(1-N 3) \div N 3] \times[N 2 \div(1-N 2)]$

$\theta \quad$ cut

$=$ molar flow in product stream (hot outlet $) \div N 1$

\section{References}

Balas, M., Lisy, M., KubiceK, J., And PospisiL, J. 2014. Syngas cleaning by wet scrubber. WSEAS Transactions on Heat and MaSS Transfer, vol. 9. pp. 195-204.

Balepin, V., Rosshold, D., and Petley, D. 1999. Progress in air separation with the vortex tube. Proceedings of the 9th International Space Planes and Hypersonic Systems and Technologies Conference, Norfolk, VA, 1-5 November 1999. NASA Langley Research Center, Hampton, VA. https://ntrs.nasa.gov/search.jsp?R=20000012624

BinAu, N.J. 1997. Assessment of air separation technologies for the recovery of oxygen for use in hypersonic flight. MSc thesis, Montana State University, Bozeman, MT.

Chatterjee, M., Mukhopadhyay, S., and Vijayan, P.K. 2017. 1-D model for mass transfer calculation in vortex tube using heat and mass transfer analogy. American Journal of Heat and Mass Transfer, vol. 4, no. 1. pp. 1-24.

Chentsov, A.V., Beloglazov, V., and Korsakov, V. 2009. Methods for cleaning off-gas, based on gas-dynamic effects, not previously used in production. 


\section{Conceptual use of vortex technologies for syngas purification and separation}

(Сборник Докладов Второй Международной Конференции: «Пылегазоочистка-2009). Collection of reports of the Second International Conference 'Dust-Exposure', September 2009. pp. 62-66. http://www.multifilter.ru/pdf/news/intecheco2009ecolog_reports.pdf

Chentsov, A.V. and BARsukov, B.N. 2011. Gas dynamic methods - dry cleaning of waste gases. (Газодинамические Способы, Сухой Очистки Отходящих Газов). Environmental Journal of Russia, Ecology and Technology, vol. 4. pp. 40-44.

http://bnbars.moy.su/vihr_statia/STATIA_1.pdf

DUTTA, T., SinhamahapatRA, K.P., and BandyopadhyAY, S.S. 2011. Numerical investigation of gas species and energy separation in the Ranque-Hilsch vortex tube using real gas model. International Journal of Refrigeration, vol. 34. pp. 2118-2128.

FArouk, T., FARouk, B., and GuTSOL, A. 2009. Simulation of gas species and temperature separation in the counter-flow Ranque-Hilsch vortex tube using the large eddy simulation technique. International Journal of Heat and Mass Transfer, vol. 52, no. 13-14. pp. 3320-3333.

Federal Remediation Technologies Roundtable. 2016. Remediation technologies, screening matrix and reference guide, Version 4.0. Air emissions/off-gas treatment/scrubbers. http://www.frtr.gov/matrix2/section4/4-60.html [accessed May 2018].

Gu, Z., ZHAo, Y., LI, Y., Yu, Y., and FenG, X. 2006. A numerical simulation of dust lifting within dust devils-simulation of an intense vortex. Journal of the Atmospheric Sciences, vol. 63. pp. 2630-2641.

Guan, X., Gardner, B., Martin, R., and Spain, J. 2008. Demonstration of hot gas filtration in advanced coal gasification system. Powder Technology, vol. 180 , no. 1-2. pp. 122-128.

HaGHiGHI, M., HAwBoLdT, K.A., and ABdi, M.A. 2015. Supersonic gas separators: Review of latest developments. Journal of Natural Gas Science and Engineering, vol. 27. pp. 109-121.

Hirohata, O., Wakabayashi, T., Tasaka, K., Fushimi, C., Furusawa, T., Kuchonthara, P., and Tsutsumi, A. 2008. Release behavior of tar and alkali and alkaline earth metals during biomass steam gasification. Energy \& Fuels, vol. 22, no. 6. pp. 4235-4239.

KorsAKov, V.A. 2010. Alternative highly effective technological solutions, based on physical effects, not previously used in industry. (Научнопрактическая конференция: «Инновационное предпринимательство: от идеи до внедрения»). Proceedings of the Scientific and Practical Conference: 'nnovative Entrepreneurship: From Idea to Implementation', 26-27 May 2010. pp. 22-30. http://omskmark.moy.su/publ/innovatica/marketing/2010_korsakov_v_a_ alternativnye_vysokoehffektivnye/11-1-0-75 (accessed May 2018]

KULKARNI, M.R. and SARDESAI, C.R. 2002. Enrichment of methane concentration via separation of gases using vortex tubes. Journal of Energy Engineering, vol. 128 , no. 1. pp. 1-12.

LindERSTROM-LANG, C. 1964. Gas separation in the Ranque-Hilsch vortex tube. International Journal of Heat and Mass Transfer, vol 7. pp. 1195-1206.

LINDERSTROM-LANG, C. 1966. Gas separation in the Ranque-Hilsch vortex tube Model calculations based on flow data. Forskningscenter Risoe. Risoe-R, no. 135 . Risø, Denmark.

MARSHALL, J. 1976. Effect of operating conditions, physical size and fluid characteristics on the gas separation performance of a Linderstrom-Lang vortex tube. International Journal of Heat and Mass Transfer, vol. 20. pp. 227-231.

Moiseev, V.A., PiletskiI, V.G., Andrienko, V.G., Tailakov, O.V., and Chentsov, A.V. 2016a. The technological and design solutions for energy vortex gas separation of the ventilation and degasification emissions from coal mines using gradient separators. Global Journal of Pure and Applied Mathematics, vol. 12, no. 1. pp. 559-574.

Moiseev, V.A., Andrienko, V.G., PiletskiI, V.G., Makotrenko, V.A., and Chentsov, A.V. 2016b. Technology of recovering mechanical impurities from ventilation and degasification emissions from coal mines. Research Journal of Pharmaceutical, Biological and Chemical Sciences, vol. 7, no. 5. pp. 397-402.

National Lime Association. 2007. Flue gas desulfurization technology evaluation - lime vs. limestone. Project Number 11311-001, Comparison Report 20070315 (March 2007). https://www.lime.org/documents/ publications/free_downloads/fgdte_dry-wet-limestone2007.pdf [accessed May 2018].

NetuŠIL, M. and DitL, P. 2012. Natural gas dehydration. InTech. doi: $10.5772 / 45802$

Parsley, D., Ciora, R.J. JR., Flowers, D.L., Laukaitaus, J., Chen, A., Liu, P.K.T, Yu, J., Bonsu, M.S.A., and TsoTsIs, T.T. 2014. Field evaluation of carbon molecular sieve membranes for the separation and purification of hydrogen from coal-and biomass-derived syngas. Journal of Membrane Science, vol. 450. pp. 81-92.

Prabhansu, M., Karmakar, K.R., Chandra, P., and Chatterjee, P. 2015. A review on the fuel gas cleaning technologies in gasification process. Journal of Environmental Chemical Engineering, vol. 3. pp. 689-702.

RTI LLC., 2018. Warm gas desulfurization process technology. https://www.rti.org/impact/warm-gas-desulfurization-process-technology [accessed May 2018].

SCHEIBNER, B. and Wolters, C. 2002. Schumacher hot gas filter long-term operating experience in the nuon power buggenum IGCC power plant. Proceedings of the 5th International Symposium on Gas Cleaning at High Temperature, 17-20 September 2002. https://www.netl.doe.gov/ File\%20Library/Events/2002/gas\%20cleaning\%20at\%20high\%20tempera ture/1-05paper.pdf

Secchi, R., InNocentI, G., and FIASCHI, D. 2016. Supersonic swirling separator for natural gas heavy fractions extraction: 1D model with real gas EOS for preliminary design. Journal of Natural Gas Science and Engineering, vol. 34. pp. 197-215

Sforza, P.M., CAStrogiovanni, A., and Voland, R. 2012. Coal-derived syngas purification and hydrogen separation in a supersonic swirl tube. Applied Thermal Engineering, vol. 49. pp. 154-160.

Sharma, S.D., Dolan, M., Park, D., Morpeth, L., IlyushechKin, A., McLennan, K. HARRIs, D.J., and ThAmbimuthu, K.V. 2008. A critical review of syngas cleaning technologies - fundamental limitations and practical problems. Powder Technology, vol. 180. pp. 115-121.

SPRACKLEN, N.M. 1998. Preliminary investigation of the separation of a binary, two-phase hydrocarbon mixture using a commercially available vortex tube, MSc thesis, Montana State University, Bozeman, MT.

STUDOPEDIA. Not dated. Dry inert gas cleaning. (Газдарды құрғақ инерциялық тазалау аппараттары). Paragraphs 6.8 and 6.9. https://studopedia.org/1-9846.html [accessed May 2018].

Swansoen, M.L. and HajICEK, D.R. 2002. Hot-gas filter testing with a transport reactor gasifier. Proceedings of the 5th International Symposium on Gas Cleaning at High Temperature, 17-20 September 2002.

Theunissen, T., GolomboK, M., Brouwers, J.J.H., Bansal, G., and van Benthum, R. 2011. Liquid $\mathrm{CO} 2$ droplet extraction from gases. Energy, vol. 36. pp. 2961-2967.

Torres, W., PANSARE, S.S., and Goodwin, J.G. 2007. Hot gas removal of tars, ammonia, and hydrogen sulfide from Biomass gasification gas. Catalysis Reviews - Science and Engineering, vol. 49, no. 4. pp. 47-56.

VAN DyK, J.C. and KeYSER, M.J. 2014. Influence of discard mineral matter on slag-liquid formation and ash melting properties of coal - A Factsage ${ }^{\mathrm{TM}}$ simulation. Fuel, vol. 116 (January). pp. 834-840.

VAN DyK, J.C., BRAnd, J.F., and WAANDERS, F.B. 2014. Equilibrium coal mineral matter simulation and slag formation during an underground coal gasification process. Proceedings of the 6th International Freiberg Conference on IGCC \& XtL Technologies, Freiberg, Germany, 19-22 May 2014. TU Bergakademie, Freiberg. https://tufreiberg.de/sites/default/files/media/professur-fuerenergieverfahrenstechnik-und-thermische-rueckstandsbehandlung16460/publikationen/2014-17-2.pdf

WANG, L.K., PEREIRA, N.C., and Hung, Y.T. 2005. Desulfurization and emissions control. Handbook of Environmental Engineering, Vol 2: Advanced Air and Noise Pollution Control. Springer. pp. 35-95.

WIKIPEDIA. 2018. https://en.wikipedia.org/wiki/Vortex_tube [accessed May 2018]

WooLcock, P.J. and Brown, R.C. 2013. A review of cleaning technologies for biomass-derived syngas. Biomass and Bioenergy, vol. 52. pp. 54-84.

Xue, Y., ARjomandi, M., and Kelso, R. 2013. The working principle of a vortex tube. International Journal of Refrigeration, vol. 36. pp. 1730-1740. 